\title{
Lymphangioma in Patients with Pulmonary Lymphangioleiomyomatosis: Results of Sirolimus Treatment
}

Elżbieta Radzikowska ${ }^{1 *}$, Katarzyna Błasińska-Przerwa ${ }^{2}$, Paulina Skrońska ${ }^{3}$, Elżbieta Wiatr ${ }^{1}$, Tomasz Świtaj ${ }^{4}$, Agnieszka Skoczylas $^{5}$ and Kazimierz Roszkowski-Śliż

${ }^{1}$ Department of Lung Diseases, National Tuberculosis and Lung Diseases Research Institute, Warsaw, Poland ${ }^{2}$ Department of Radiology, National Tuberculosis and Lung Diseases Research Institute, Warsaw, Poland

${ }^{3}$ Department of Genetics and Clinical Immunology, National Tuberculosis and Lung Diseases Research Institute, Warsaw, Poland

${ }^{4}$ Department of Soft Tissue/Bone Sarcoma and Melanoma, Maria Skłodowska-Curie Memorial Cancer Centre and Institute of Oncology, Warsaw, Poland ${ }^{5}$ Department of Geriatrics, National Institute of Geriatrics, Rheumatology and Rehabilitation, Warsaw, Poland

\begin{abstract}
Objective: Lymphangioleiomyomatosis (LAM) is a rare disease caused by abnormal proliferation of smooth muscle-like cells mainly in lungs and axial lymph nodes, that belongs to the group of PEComa tumours. Chylous pleural and abdominal effusions, lymhangioleiomiomas, angiomyolipomas are noticed in disease course. Sirolimus has been approved for LAM treatment, and also it has been reported to decrease the size of angiomyolipomas, lymphangiooedma, pleural and peritoneal chylous effusion. The aim of the study was to assess the significance of sirolimus therapy in patients with LAM and lymphangioma in retroperitoneal space.
\end{abstract}

Method: Fourteen women with confirmed diagnosis of LAM (13 with sporadic LAM, and one TSC/LAM) and presence of lymphangioma in abdominal cavity were retrospectively reviewed. Seven patients displayed chyloperitoneum and chylothorax. Mean time of sirolimus exposure was $19 \pm 12.99$ months.

Results: After ten months of treatment a complete regression of chylothorax and chyloperitoneum occurred in 13 patients, and partial regression occurred in one patient. Treatment resulted in decrease of lymphangioma volume $\left(1603.85 \pm 2437.56 \mathrm{~cm}^{3}\right.$ vs. $\left.198.01 \pm 315.43 \mathrm{~cm}^{3} ; p=0.00026\right)$, stabilisation of pulmonary function parameters such as (FVC, FEV1, TLC, DLCO), improvement of distance in 6MWT (514.46 $\pm 101.72 \mathrm{~m}$ vs. $526.79 \pm 139.33$ $\mathrm{m} ; p=0.002)$, blood oxygenation $(68.93 \pm 13.6 \mathrm{mmHg}$ vs. $78.23 \pm 11.14 \mathrm{mmHg} ; p=0.04)$, and decrease of serum VEGF-D concentration $(2591 \pm 1085 \mathrm{pg} / \mathrm{mL}$ vs. $1274 \pm 708 \mathrm{pg} / \mathrm{mL} ; p=0.003)$.

Conclusion: Sirolimus has proved to be an effective treatment of lymphangioma, chylous pleural and peritoneal effusions in LAM patients.

Keywords: LAM; Lymphangioleiomyomatosis; Lymphangioma; Sirolimus; Tuberous sclerosis; VEGF-D

Abbreviations: sLAM: Sporadic Lymphangioleiomyomatosis; TSC/LAM: Tuberous Sclerosis/Lymphangioleiomyomatosis; VEGF-D: Vascular Endothelial Growth Factor D; FVC: Forced Vital Capacity; FEV1: Forced Expiratory Volume in 1 second; TLC: Total Lung Capacity; RV: Residual Volume; DL, CO: Diffusion Lung Capacity for Carbon Monoxide; 6MWT: 6 Minute Walk Test; $\mathrm{PaO}_{2}$ : Partial Pressure of Oxygen in the Blood; $\mathrm{PaCO}_{2}$ : Partial Pressure of Carbon Dioxide in the Blood; HRCT: High Resolution Computed Tomography; mTOR: mammalian Target of Rapamycin Kinase; PEComa: Perivascular Epithelioid Cell tumours

\section{Introduction}

Lymphangioleiomyomatosis (LAM) is a rare disease caused by proliferation of abnormal smooth muscle-like cells (LAM cells), which can result in cystic destruction of lungs, formation of renal angiomyolipomas, lymphadenopathy, cystic lymphangiomas, abdominal lymphangioleiomyomas, chylothorax, and chyloperitoneum $[1,2]$. It is a low-grade metastasizing neoplasm spreading through lymphatic routs and belongs to the group of the PEComas (perivascular epithelioid cell tumours) [1]. This disease affects mainly women in childbearing age and occurs in two forms: As a sporadic lymphangioleiomyomatosis (sLAM) or associated with tuberous sclerosis complex (TSC-LAM). The incidence of sLAM is about 3.4/ million to $7.5 /$ million women, and it was assessed that approximately 0.3 million to 0.4 million of women with tuberous sclerosis (TSC) have a LAM [1-3].
The important molecular mechanism leading to LAM development and progression is the loss of TSC1 or TSC2 gene function. It results in the mTOR signalling pathway activation and subsequently dysregulation of cell growth, survival and motility up-regulation [4]. Patients with sporadic LAM are mainly carriers of somatic mutations in the TSC2 or TSC1 genes. Patients with TSC/LAM, have an autosomal, dominant inherited disease, and a mutant copy of both TSC genes is transferred through the germline. The inactivation of the second allele of either gene by loss of heterozygosity or by promoter methylation results in development of several hamartomatous tumors in skin, brain, kidney, lungs, heart, liver and retina. It is a disorder with variable penetrance, which can create wide clinical spectrum of the disease [1-3].

The presence of lymphangiomas in the abdominal or thoracic cavity is observed in about $25 \%$ of LAM patients, but chylous effusion in $10 \%$

*Corresponding author: Radzikowska E, Department of Lung Diseases, Nationa Tuberculosis and Lung Diseases Research Institute, Płocka 26, St. 01-138, Warsaw Poland, Tel: +48224312229; Fax + 48 224312408; E-mail: e.radzikowska@wp.pl

Received August 21, 2016; Accepted September 26, 2016; Published September 28, 2016

Citation: Radzikowska E, Błasińska-Przerwa K, Skrońska P, Wiatr E, Świtaj T, et al. (2016) Lymphangioma in Patients with Pulmonary Lymphangioleiomyomatosis: Results of Sirolimus Treatment. J Cancer Sci Ther 8: 233-239. doi: 10.4172/19485956.1000419

Copyright: (C) 2016 Radzikowska E, et al. This is an open-access article distributed under the terms of the Creative Commons Attribution License, which permits unrestricted use, distribution, and reproduction in any medium, provided the original author and source are credited. 
to $15 \%$ of patients. Both these conditions can cause severe symptoms such as dyspnoea, pain, male absorption, weight loss, gastrointestinal or urinary tract obstructions $[1,3,5]$.

Previous treatments: drainage of pleural and peritoneal cavities, thoracic duct ligation, pleurodesis or hormonal manipulations, octerotide, low fat or parenteral diets, were not sufficiently effective $[1,6]$.

There is a growing number of evidence, that inhibitors of mTOR kinase can be very effective therapy in LAM patients with this particular clinical presentation [6-17].

Sirolimus belongs to the group of mTOR inhibitors and was proved to be effective in a decrease of angiomyolipomas volume, chylous pleural and peritoneal effusion, lymphedema, lymphangioma and to stabilize the pulmonary function in LAM patients $[6,8-16]$.

LAM is a very rare disease. The number of patients with LAM and lymphangioma previously enrolled into the studies with mTOR inhibitors, and particularly those who finished them, was rather small.

The study was conducted to assess the effect of sirolimus treatment in LAM patients with lymphangioma, and/or chylothorax, and/or chyloperitoneum. In addition, the value of VEGF-D serum concentration in monitoring of disease regression was analysed.

\section{Material and Methods}

\section{Study population}

The study group consisted of retrospectively evaluated patients, with characteristic radiological presentation of cystic abnormalities in chest high resolution computed tomography (HRCT), including 13 women with sLAM and 1 patient with TSC-LAM complex. Final diagnosis of LAM was based on clinical and radiological examination, and was confirmed by histological assessment of tissue material in 13 cases. In one patient diagnosis of sLAM was based on the typical clinical and the radiological findings, presence of the lymphangioma, and high (above $800 \mathrm{pg} / \mathrm{mL}$ ) serum VEGF-D concentration. One patient met the criteria of definite TSC.

Pulmonary function tests were performed according to the joint guidelines of the American thoracic society and the European respiratory society [17]. The lung volumes were measured by the body plethysmography (Jeager Master Screen software version 4; Wuerzburg; Germany) and a diffusing capacity for carbon monoxide ( $D \mathrm{~L}, \mathrm{CO}$ ) using the single breath technique. Absolute values and percentages of predicted values were analysed.

The 6-min walk test (6MWT) was performed according to the recommendations [18].

The lung involvement in HRCT was graded according to proposition of Avila et al. In the first group cystic lesions involved less than $30 \%$, in second $30 \%$ to $60 \%$, and in third over $60 \%$ of the equally divided three zones of the lungs [19].

Magnetic resonance imaging was used for the lymphangioma assessment. The abdomen and pelvis MRI examinations (Avanto, Siemens $1.5 \mathrm{~T}$ ) were performed with intravenous contrast administration (Multihance $0.2 \mathrm{ml} / \mathrm{kg}$ ). Three-planes scans were acquired.

T2-weighted BLADE images with and without fat saturation, T2weighted TrueFISP, DWI/ADC, pre- and post-contrast T1-weighted VIBE images with fat saturation, T1-weighted images with chemical shift technique were obtained.
Serum VEGF-D concentrations were measured by the quantitative sandwich enzyme immunoassay technique (R\&D Systems, Minneapolis, $\mathrm{MN}, \mathrm{USA}$ ), in accordance to the manufacturer recommendations as presented earlier [20].

Sirolimus was administered in oral dose allowing to obtaine the serum level between $5 \mathrm{ng} / \mathrm{mL}$ to $15 \mathrm{ng} / \mathrm{mL}$, usually $1 \mathrm{mg} / \mathrm{d}$ to $5 \mathrm{mg} / \mathrm{d}$.

At the beginning of the treatment patients were assessed after 2 and 4 weeks. Subsequently they had a visit every 3 months. During these visits patients underwent standard blood and urinary tests, measurement of serum sirolimus level, and chest radiography in the cause of indication. Pulmonary function tests were done after first 4 months of the treatment and after 6 and 12 months thereafter. Chest computed tomography was performed after 10 months and subsequently once a year. VEGF-D measurements were performed once a year. Magnetic resonance imaging of abdominal and pelvic cavities was performed after first 4 months of the treatment and subsequently after 6 months, and every 12 months thereafter.

Adverse events were recorded on each visit and were assessed with the use of the Common Terminology Criteria for Adverse Events (version 4.0). Patient received off-label sirolimus treatment and signed the informed consent. The study was supported by the National Tuberculosis and Lung Diseases Research Institute grant no. 7.22. The national tuberculosis and lung diseases research institute bioethics committee approved the study.

\section{Statistical analysis}

Statistic computations were performed using the $\mathrm{R}$ environment. Distribution normality in examined groups was assessed by the ShapiroWilk test and homogeneity of variance was assessed by the Levene test. If both test results were non-significant, one way repeated measures ANOVA was used, otherwise non parametric test-the Friedman test was performed. Post hoc the Quade test and the Nemenyi test were applied respectively if applicable.

The Wilcoxon test or the Student's t-test for dependent means were also applied. A value of probability $(p)<0.05$ was considered as statistically significant. P-values are two-sided and unadjusted for multiple testing. Data were reported as means (SDs).

\section{Results}

\section{Study population}

All patients had large lymphangiomas in the retroperitoneal region, 7 patients had chyloperitoneum, 7 chylothorax, and 4 renal angiomyolipomas. In 3 patients PEComa tumours in pelvis were revealed, and partially resected. Ligation of chylous duct was performed in 5 patients. Seven patients before treatment had pneumothorax (19 episodes). No patient had pneumothorax after initiation of the treatment.

Three patients were ex-smokers (2 patients smoked 2 pack/years and one patient $1 /$ pack year) and the rest were non-smokers.

All patients had signs or symptoms of the abdominal lesions (pain, full effect filling, enlargement of abdomen). Patients with pleural fluid had chest discomfort and effort dyspnoea. One woman had a respiratory insufficiency and received the oxygen therapy. Loss of weight (more than $10 \%$ in the last three months) was observed in 7 patients.

Concomitant diseases diagnosed in our patients were: Allergy ( 7 patients) asthma (5 patients), arterial hypertension (3 patients), irritable 
Citation: Radzikowska E, Błasińska-Przerwa K, Skrońska P, Wiatr E, Świtaj T, et al. (2016) Lymphangioma in Patients with Pulmonary Lymphangioleiomyomatosis: Results of Sirolimus Treatment. J Cancer Sci Ther 8: 233-239. doi: 10.4172/1948-5956.1000419

bowel disease ( 3 patients), hypothyreosis ( 2 patients), intolerance of lactose (1 patient), depression (1 patient), pituitary cyst (1 patient), meningioma (1 patient), large bowel diverticula (1 patient), varicose curries (1patient), pseudolupus syndrome (1 patient), and epilepsy (1 patient).

The mean age of patients, at the time of sirolimus introduction was $41 \pm 10.78$ years. Two patients were menopausal.

The mean diagnosis delay (time between first symptom(s) and the time of diagnosis) was $45.43 \pm 79.4$ months. The period between diagnosis and treatment introduction was $60.21 \pm 83.86$ months.

Two patients before sirolimus were treated with medroxyprogesterone. One of them was diagnosed 13 years earlier in the other hospital, and she was treated with medroxyprogesterone and tamoxifen. This patient has developed meningiomas. One patient with PEComa in the pelvis cavity was treated ineffectively with chemotherapy in the other hospital.
The mean time of the sirolimus exposure was $19 \pm 12.99$ months.

Patients were under the observation in our centre for the mean time of $35.1 \pm 28.6$ months.

\section{HRCT scoring}

All patients had pulmonary high resolution computed tomography (HRCT). The mean HRCT score before study (according to Avila et co.) was $2.43 \pm 0.64$, and 10 months after it did not change (13 patients).

\section{Pulmonary function tests}

The results of pulmonary function tests of 14 patients (at the beginning, one woman with respiratory insufficiency was not able to make full plethysmography) were presented in Tables 1 and 2 . Individual values of FVC, FEV1, TLC, DLCO, and distance in 6MWT were shown in Figures 1-5.

The mean value of $\mathrm{PaO}_{2}$ significantly increased during the treatment

\begin{tabular}{|c|c|c|c|c|c|}
\hline & Before the treatment & After 4 months of the treatment & $p$ & After 10 months of the treatment & $p$ \\
\hline FVC (L) Mean \pm SD & $3.11 \pm 0.82$ & $3.28 \pm 0.85$ & 0.682 & $3.25 \pm 0.87$ & 0.952 \\
\hline FVC $\%$ pred. Mean \pm SD & $86.86 \pm 21.25$ & $91.57 \pm 19.26$ & 0.384 & $91.57 \pm 17.88$ & 0.384 \\
\hline FEV1 (L) Mean \pm SD & $2.11 \pm 0.5$ & $2.3 \pm 0.65$ & 0.116 & $2.33 \pm 0.64$ & 0.116 \\
\hline FEV1 $\%$ pred. Mean \pm SD & $69.23 \pm 12.43$ & $74.43 \pm 17.81$ & 0.22 & $75.95 \pm 16.86$ & 0.066 \\
\hline TLC $(\mathrm{L})$ Mean $\pm \mathrm{SD}$ & $5.32 \pm 1.27$ & $5.51 \pm 1.14$ & 0.509 & $5.5 \pm 1.23$ & 0.549 \\
\hline TLC $\%$ pred. Mean \pm SD & $105.9 \pm 21.88$ & $110.79 \pm 23.27$ & 0.327 & $109.5 \pm 22.07$ & 0.548 \\
\hline RV (L) Mean \pm SD & $2.25 \pm 0.23$ & $2.28 \pm 0.72$ & 0.529 & $2.23 \pm 0.77$ & 0.596 \\
\hline RV \% pred. Mean \pm SD & $140.43 \pm 39.44$ & $131.5 \pm 30.97$ & 0.472 & $138.36 \pm 45.8$ & 0.844 \\
\hline $\mathrm{DLCO} \mathrm{mL} / \mathrm{min} / \mathrm{mmHg}$ Mean $\pm \mathrm{SD}$ & $3.78 \pm 1.43$ & $4.05 \pm 1.65$ & 0.61 & $3.95 \pm 1.38$ & 0.83 \\
\hline DLCO $\%$ pred. Mean \pm SD & $43.92 \pm 18.76$ & $46.71 \pm 17.55$ & 0.704 & $46.03 \pm 13.93$ & 0.811 \\
\hline $\begin{array}{l}\text { 6MWT distance }(\mathrm{m}) \\
\text { Mean } \pm \text { SD }\end{array}$ & $514.46 \pm 101.72$ & $507.14 \pm 135.16$ & 0.384 & $526.79 \pm 139.33$ & 0.087 \\
\hline Desaturation Mean \pm SD & $7.62 \pm 4.75$ & $7.36 \pm 4.81$ & 0.535 & $6.71 \pm 5.13$ & 0.827 \\
\hline $\mathrm{PaO}_{2} \mathrm{mmHg}$ Mean $\pm \mathrm{SD}$ & $68.93 \pm 13.6$ & $76.14 \pm 10.44$ & 0.002 & $78.23 \pm 11.14$ & 0.002 \\
\hline $\mathrm{PaCO}_{2} \mathrm{mmHg}$ Mean $\pm \mathrm{SD}$ & $31.31 \pm 3.54$ & $34.86 \pm 2.98$ & 0.004 & $33.23 \pm 3.54$ & 0.055 \\
\hline
\end{tabular}

Table 1: Pulmonary function parameters in LAM patients before the treatment, 4 and 10 months after beginning of the therapy.

\begin{tabular}{|c|c|c|c|c|c|}
\hline Variable & Shapiro-Wilk tests & Levene test & $p$-value & Post-hoc test & $p$-values in post-hoc \\
\hline $\mathrm{VC}(\mathrm{L})$ & NS & 0.963 & 0.486 & - & - \\
\hline VC (\% pred) & NS & 0.781 & 0.364 & - & - \\
\hline FEV1 (L) & NS & 0.548 & 0.119 & - & - \\
\hline FEV1 (\% pred) & NS & 0.874 & 0.106 & - & - \\
\hline TLC (L) & NS & 0.948 & 0.424 & - & - \\
\hline TLC (\% pred) & NS & 0.892 & 0.322 & - & - \\
\hline $\mathrm{RV}(\mathrm{L})$ & NS & 0.970 & 0.8 & - & - \\
\hline RV \% pred. & NS & 0.960 & 0.705 & - & - \\
\hline $\mathrm{DLCO}(\mathrm{mL} / \mathrm{min} / \mathrm{mmHg})$ & NS & 0.701 & 0.359 & - & - \\
\hline DLCO \% pred. & NS & 0.546 & 0.405 & - & - \\
\hline Distance $(m)$ & $\begin{array}{c}0.009 \text { in M4 } \\
0.004 \text { in M10 data set }\end{array}$ & 0.959 & 0.011 & Nemenyi test & $\begin{array}{l}\text { M } 0 \text { vs. M10: } 0.012 \\
\text { M } 0 \text { vs. M 4: } 0.409 \\
\text { M } 4 \text { vs. M10: } 0.259\end{array}$ \\
\hline $\mathrm{PO}_{2}(\mathrm{mmHg})$ & NS & 0.912 & $2.47 \times 10^{-5}$ & Quade test & $\begin{array}{l}\text { M0 vs. M10: } 0.004 \\
\text { M0 vs. M4: } 0.00027 \\
\text { M4 vs. M10: } 0.238\end{array}$ \\
\hline $\mathrm{PCO}_{2}(\mathrm{mmHg})$ & NS & 0.780 & 0.023 & Quade test & $\begin{array}{l}\text { M0 vs. M10: } 0.003 \\
\text { M0 vs. M4: } 0.113 \\
\text { M4 vs. M10: } 0.099\end{array}$ \\
\hline Lyphangioma $\left(\mathrm{cm}^{3}\right)$ & $\begin{array}{c}0.0002 \text { for } M 0 \\
0.0037 \text { for } M 4 \\
0.00035 \text { for } M 10 \text { data set }\end{array}$ & 0.068 & 0.00026 & Nemenyi test & $\begin{array}{c}\text { M0 vs. M10: } 0.00026 \\
\text { M0 vs. M4: } 0.029 \\
\text { M4 vs. M10: } 0.355\end{array}$ \\
\hline
\end{tabular}

Table 2: Pulmonary function parameters and lymphangioma volume before the treatment (M0), 4 (M4) and 10 (10 M) months after beginning of the therapy-one way repeated measures ANOVA and the Friedman test results. 
Citation: Radzikowska E, Błasińska-Przerwa K, Skrońska P, Wiatr E, Świtaj T, et al. (2016) Lymphangioma in Patients with Pulmonary Lymphangioleiomyomatosis: Results of Sirolimus Treatment. J Cancer Sci Ther 8: 233-239. doi: 10.4172/1948-5956.1000419

$(68.93 \mathrm{mmHg} \pm 13.6 \mathrm{mmHg}$ vs. $76.14 \mathrm{mmHg} \pm 10.44 \mathrm{mmHg}$ vs. 78.23 $\mathrm{mmHg} \pm 11.14 \mathrm{mmHg}: \mathrm{p}<0.004)$ after 4 and 10 months respectively.

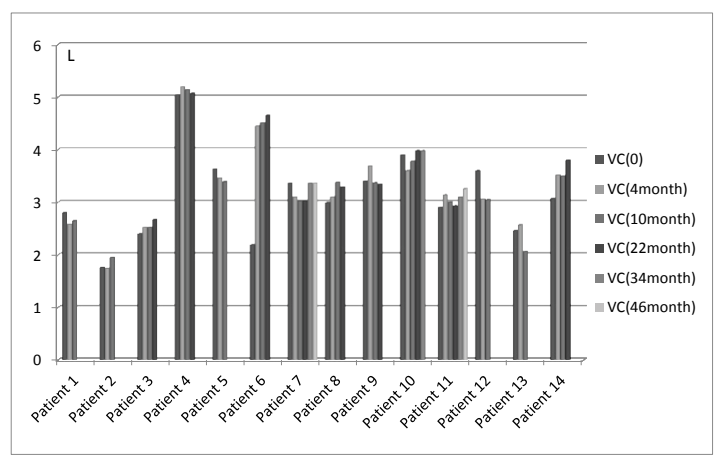

Figure 1: Individual values of FVC (L) during the time of observation.

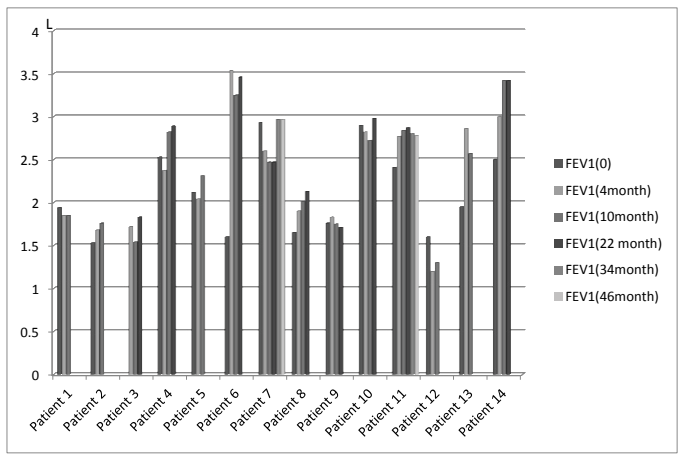

Figure 2: Individual values of FEV1(L) during the time of observation.

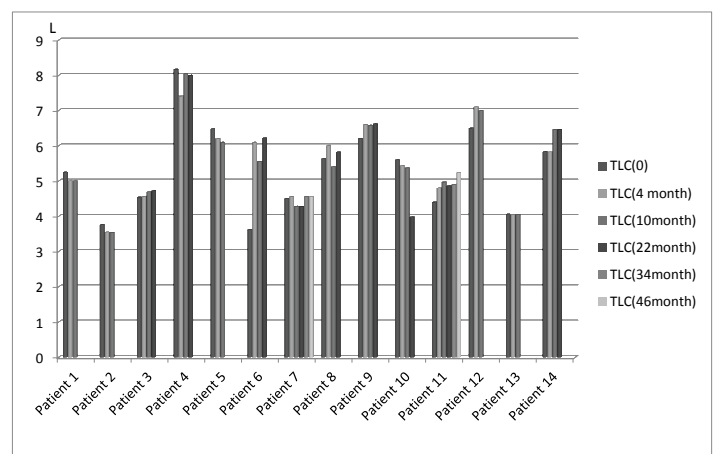

Figure 3: Individual values of TLC (L) during the time of observation.

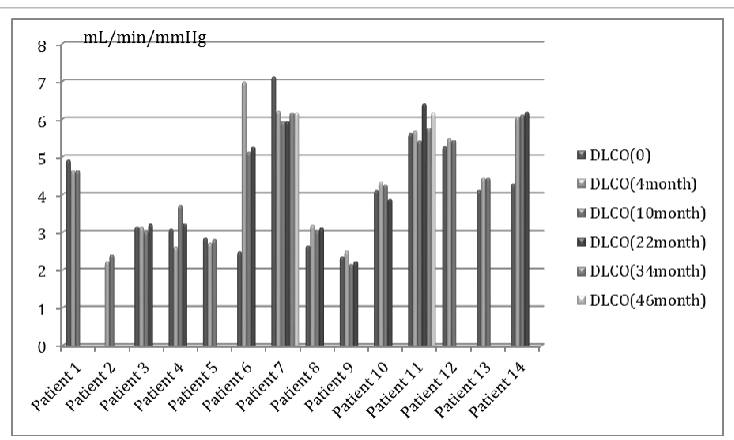

Figure 4: Individual values of DLCO $(\mathrm{mL} / \mathrm{min} / \mathrm{mmHg})$ during the time of observation.

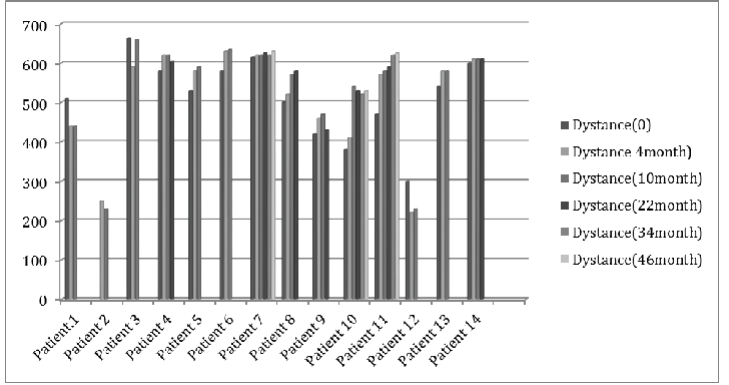

Figure 5: Individual values of distance $(\mathrm{m})$ in 6MWT during the time of observation.

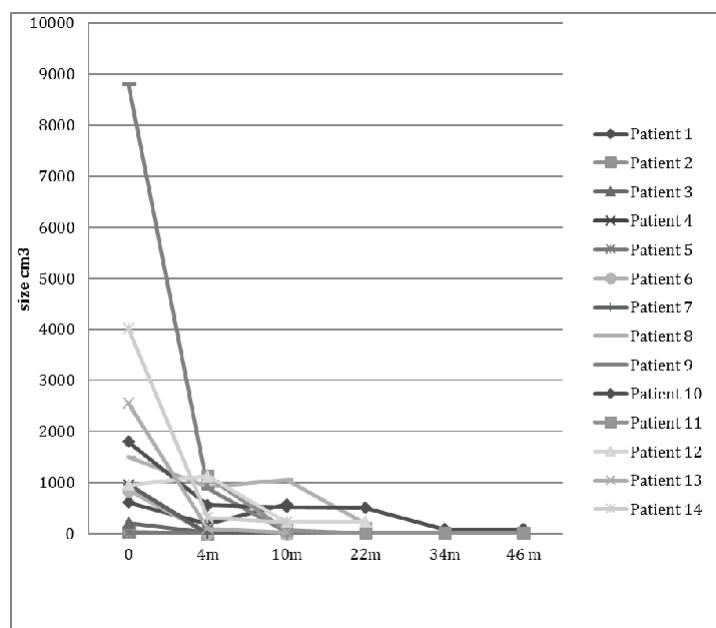

Figure 6: Individual values of lymphangioma volume $\left(\mathrm{cm}^{3}\right)$ during the time of observation.

Also increase of mean values of $\mathrm{PaCO}_{2}(31.31 \mathrm{mmHg} \pm 3.54 \mathrm{mmHg}$ vs. 34.86; $2.98 \mathrm{mmHg}$ vs. 33.23, $3.54 \mathrm{mmHg} ; \mathrm{p}<0.003)$, after 4 and 10 months of the therapy was noticed.

Despite, that sirolimus treatment resulted in increase of the mean values of FVC $(+140 \mathrm{~mL})$, FEV1 $(+220 \mathrm{~mL})$, TLC $(+180 \mathrm{~mL})$, and decrease of the mean values of RV $(-20 \mathrm{~mL})$ but the differences did not reach the significance. Additionally, after 10 months of the treatment patients walked slightly longer distance in 6MWT $(514 \pm 101.72 \mathrm{~m}$ vs. $526 \pm 139.33 \mathrm{~m} ; \mathrm{p}=0.012$ ), with less, but insignificant desaturation (7.62 \pm 4.75 vs. $6.71 \pm 5.13 ; \mathrm{p}=0.307)$.

After 4 months of sirolimus treatment substantial improvement of pulmonary function was observed in patients with large amount of pleural effusion (Patient 2,4,6,11,13,14).

\section{Chylous effusions}

At enrolment, 7 patients had the chyloperitoneum, and three of them were treated by surgery, due to tumours in the pelvic cavity. Chylous pleural effusion was noticed in 7 patients and they had pleurodesis. Additionally, 5 patients were treated with ligation of the main lymphatic duct. Six patients had a thoracentesis and 3 paracenthesis. The large amounts of pleural and peritoneal fluid were noticed in six patients, and small peritoneal effusion was present in one patient. After first 4 months of the treatment resolution of peritoneal fluid was noticed in all patients and pleural in 6 out of seven. Partial resolution of pleural effusion (over 75\%) was observed in one patient. During the time of subsequent assessment (after 10 months of treatment) no patient had pleural or peritoneal effusion. 
Citation: Radzikowska E, Błasińska-Przerwa K, Skrońska P, Wiatr E, Świtaj T, et al. (2016) Lymphangioma in Patients with Pulmonary Lymphangioleiomyomatosis: Results of Sirolimus Treatment. J Cancer Sci Ther 8: 233-239. doi: 10.4172/1948-5956.1000419

\section{Lymphangioma}

All patients had lymphangioma in the retroperitoneal space. Huge amount of peritoneal effusion disturbed assessment of large lymphangioma in patient no. 11. However, after 4 months of sirolimus treatment the chyloperitoneum resolved, and it allowed the measurements of the lymphangioma (Figure 6).

During the first 10 months of the treatment the mean volume of lymphangioma was significantly decreased $\left(1603.85 \pm 2437.56 \mathrm{~cm}^{3}\right.$ vs. $369.01 \pm 439.24 \mathrm{~cm}^{3} v s .198 .01 \pm 315.43 \mathrm{~cm}^{3}(\mathrm{p}<0.00026)$.

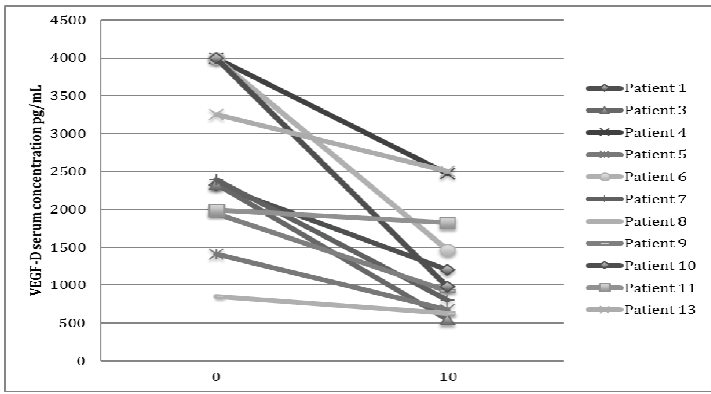

Figure 7: VEGF-D serum concentration in individual cases on the beginning of the treatemnt and after 10 months of sirolimus therapy.

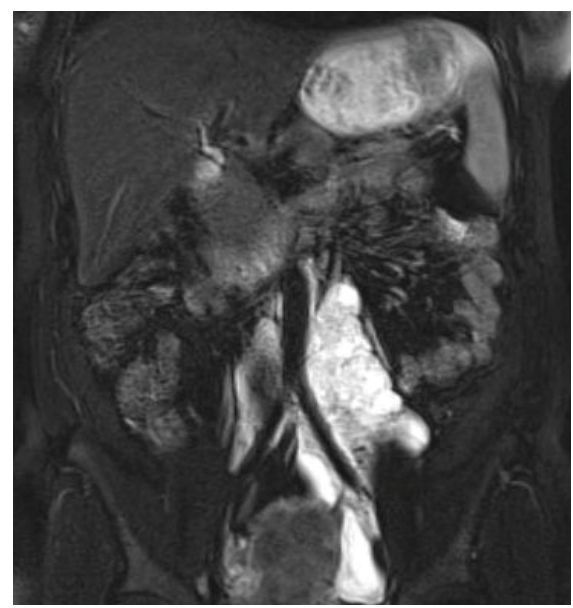

Figure 8: Patient no. 13 in the beginning of the treatment. T2-weighted coronal image with fat saturation showed a conglomerated cystic mass (lymphangioma) in the retroperitoneal space, localised along inferior vena cava and iliac veins.
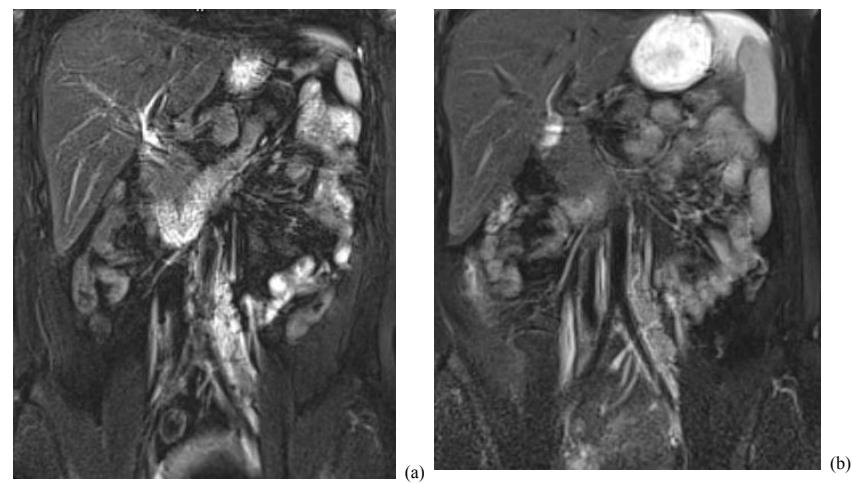

Figure 9: Patient no. 13, T2-weighted coronal images showed regression of the retroperitoneal lymphangioma after 4 months and 10 months treatment.

\section{Angiomyolipomas}

Four patients had renal angiomyolipomas. Reduction of the mean volume of angiomyolipomas was observed in all cases (17.71 \pm 20.52 $\mathrm{cm}^{3}$; after 4 months $14.93 \pm 20.88 \mathrm{~cm}^{3}$; after 10 months $12.04 \pm 16.49$ $\mathrm{cm}^{3}$ and after 22 months $10.05 \pm 17.37 \mathrm{~cm}^{3}$ ), but small number of cases influenced possibilities of statistical analysis.

\section{VEGF-D serum concentration}

The serum VEGF-D concentrations measurements were available in 10 patients (Figure 7). They ranged from $854 \mathrm{pg} / \mathrm{mL}$ to $4000 \mathrm{pg} /$ $\mathrm{mL}$, and the mean value was $2591 \mathrm{pg} / \mathrm{mL} \pm 1085 \mathrm{pg} / \mathrm{mL}$. All patients displayed the serum VEGF-D concentration higher than $800 \mathrm{pg} / \mathrm{ml}$. After ten months of the treatment a significant decrease of serum VEGF-D concentration was noticed in all patients (The mean value $1274 \mathrm{pg} / \mathrm{mL} \pm 708 \mathrm{pg} / \mathrm{mL} ; \mathrm{p}=0.003)$.

\section{Adverse events}

Adverse events of the sirolimus treatment were noticed in all patients. All of them were mild and manageable. In one patient, 61-year-old, with underling severe lactose intolerance, irritable bowel disease, and diverticula of large bowel, asthma, lupus-like syndrome, and hypothyroidism, the treatment was stopped after 10 months due to abdominal pain, discomfort and diarrhoea (all grade one of toxicity).

All patients had skin and mouth ulcers (1 grade), usually resolving spontaneously. However, all patients received topical treatment for mouth ulcers.

Ten patients experienced the upper respiratory tract respiratory infection (19 episodes-grade 1), and 3 patients had episodes of pneumonia (grade 2), treated successfully with antibiotics. Usually during the time of infection the sirolimus treatment was temporary discontinued (Figures 8 and 9).

Nausea, diarrhoea, and abdominal discomfort were observed in 3 patients, urinary tract infection and lymphedema in 2 patients. Prolong menstruations, which required temporary discontinuation of the treatment (for 4 to 5 days) were observed in one patient with TSC/ LAM, who had had this condition prior to treatment. However, after one year of sirolimus treatment, and increasing of the sirolimus dose improvement of this condition was noticed. Low fat and cholesterol diet was advised to all patients. Hypercholesterolemia was revealed in 4 patients (grade 1), and hyperlipidaemia in 2 patients (garde1). All these patients received atorvastatin with improvement. Two patients experienced liver enzymes elevation (grade 1), however they did not require any interventions.

\section{Discussion}

Our study has shown that sirolimus induced regression of the abdominal lesions, reduction of chylous and peritoneal effusions, increase of blood oxygenation and distance in 6MWT, and stabilisation of other pulmonary function parameters with strong tendency to improvement (the mean values of FVC and FEV1 increased on $+140 \mathrm{~mL}$ and $+220 \mathrm{~mL}$ respectively) in LAM patients with the lymphangioleiomyomas. In patients with angiomyolipomas also shrinking of these lesions was observed. Despite, that all patients experienced adverse events associated with sirolimus therapy, all of them were usually grade 1 , and manageable. Only one patient discontinued the therapy, because of the abdominal symptoms, but after 6 months without treatment progression of the lymphangioma was noticed. 
There are few reports describing improvement of chylous pleural and peritoneal effusions and lymphangioma lesions in the retroperitoneal space in LAM patients. da Silva et al. [13] presented the beneficial effect of sirolimus in 19 sLAM patients, 11 of them had lymphangioma and 12 had chylous effusions (11 pleural and 7 peritoneal). All their patients had complete resolution of ascites, 9 patients experienced complete resolution and 2 partial response of pleural fluid. Freitas et al. [12] showed series of 4 cases with LAM and extrapulmonary manifestations treated with sirolimus. Significant reduction of angiomyolipomas, lymphangioleiomyomas and chylous effusions was noted in these patients. Also few case reports presented positive effect of sirolimus treatment in this special group of patients. Recently Mohammadieh et al. [21] showed the beneficial effect of everolimus (another mTOR inhibitor) in treatment of the lymphangioleiomyoma and chylous effusions in a group of 6 patients with LAM.

Our patients with chylous effusions experienced spectacular effect of sirolimus treatment. The clinical, radiological, and pulmonary function parameters were improved. All patients with ascites had a complete resolution of fluid, and 6 of 7 had a complete resolution of pleural fluid. In one patient partial response of chylothorax was noticed, but she had changes for 13 years, and she has just started treatment. This patient, at the beginning had severe rest hypoxemia $\left(\mathrm{PaO}_{2}-39 \mathrm{mmHg}\right)$, but after 4 months of the treatment blood oxygenation significantly increased ( $\left.\mathrm{PaO}_{2}-59 \mathrm{mmHg}\right)$. Patients, in whom before sirolimus introduction starvation symptoms were observed, after 4 months of treatment returning to their proper weight.

Pulmonary function parameters were significantly improved in patients with pleural effusion, but other patients experienced stabilisation. For all group, similarly as McCormack et al. [8], and Yao et al. [10], we observed that sirolimus treatment was associated with stabilisation of lung function in LAM patients and increase of blood oxygenation and distance in 6MWT. In MILES trial, 46 patients treated with sirolimus in comparison with 43 patients, who received placebo, experienced improvement from baseline to 12 months of forced expiratory volume in one second (FEV1), forced vital capacity (FVC), functional residual capacity, and quality of life and functional performance. Also, Yao et al. [10] presented that sirolimus slow down lung function decline and increase of cystic lesions in 38 LAM patients treated with sirolimus. The effect remained after 3.5 years of the treatment. Additionally, in a subgroup of patients followed for 5 years a reduction of functional decline and changes in cyst score was revealed. It was suggested, that the volume of pre-existing cysts increased less during the sirolimus treatment and probably airflow obstruction, and air trapping was reduced. In our patients HRCT score did not change in a period of one year of therapy but the number of patients was too small, and observation period was short [22].

Previous studies showed, that sLAM patients with lymphangioma and with TSC/LAM had higher values of VEGF-D serum concentration than patients without these findings. In addition, the correlation between VEGF-D and chylous effusion and lymphatic involvement was suggested $[20,23,24]$. As it was presented in other studies, and in our beneficial effect of sirolimus was connected with the decrease of VEGF-D serum concentration [24]. Additionally, we noticed not only progression of lymphangioma, but also increase of serum VEGF-D concentration in woman who stopped sirolimus treatment. VEGF-D might not be the only biomarker of LAM, but also a tool for assessing disease's activity and response to the treatment $[7,8,11,22,24]$.

All presented series of patients, case reports, and also our study showed that adverse events due to sirolimus were frequent, not severe and manageable [7-9,24]. The most frequent were hypercholesterolemia (6\% to 68\%), upper respiratory tract infections (40\% to $66 \%$ ), stomatitis ( $50 \%$ to $58 \%)$, diarrhoea $(50 \%$ to $55 \%)$, peripheral oedema to $(10 \%$ to $53 \%)$, acne $(50 \%$ to $100 \%)$, stomatitis $(0 \%$ to $100 \%)$ [816]. The respiratory infections were usually not severe, but in our patients 3 episodes of pneumonia, and 2 episodes of moderately severe sinusitis (both in patients with asthma and allergic sinusitis) occured. In previously presented reports, cases of Aspergillus fumigatus infection [16] and Pneumocystis jiroveci pneumonia [22,25] were diagnosed in LAM patients with and without sirolimus treatment. In our opinion, all infections in patients treated with sirolimus should be precisely diagnosed and treated. In addition, bacterial, viral and fungal pulmonary infections have to be carefully evaluated for sirolimus induced pneumonitis.

Thelimitationsofthisstudyare:Thetypeofstudy(observational,single centre) and the number of patients. However, the disease is extremely rare, and less than $20 \%$ of LAM patients have lymphangioleiomyoma. There are suggestions that lymphangileiomyoma, chylous pleural and peritoneal effusions may have resoled spontaneously, but in some of our patients these conditions were observed for many months or years, even very aggressive surgical procedures, such as thoracic duct ligation or pleurodesis with intravenous alimentation progressive collection of pleural and peritoneal effusions were performed.

According to our observations which are consistent with data presented by da Silv et al. [13] in the era of sirolimus there is no room for pleurodesis, thoracic duct ligation, pleuroperitoneal shunts, prolong pleural or peritoneal drainage as a standard treatment of chylous pleural and peritoneal effusions in LAM patients. This type of procedures should be avoided and restricted to the special conditions such as: mTOR inhibitors intolerance, allergy or inefficiency of sirolimus.

\section{Conclusions}

Sirolimus is the important and effective treatment option in patients with LAM with lymphangioleiomyma and chylous pleural and/or peritoneal effusions. It improves the pulmonary function in patients with large pleural fluid and pulmonary lymphangiooedema, and stabilises pulmonary function in the rest of the patients.

Decrease of VEGF-D serum concentration caused by sirolimus treatment correlates with the regression of chylous effusions and lymphangioma.

Adverse events associated with the sirolimus are mild and manageable, however lifelong therapy is probably required, therefore it should be administered with caution.

\section{References}

1. Jonhson SR, Cordier JF, Lazor R, Cottin V, Costabel U, et al. (2010) European respiratory society guidelines for the diagnosis and management of lymphangioleiomyomatosis. Eur Respir J 35: 14-26.

2. Ryu JH, Moss J, Beck GJ, Lee JC, Brown KK, et al. (2006) NHLBI LAM Registry Group Characteristics of 230 patients at enrolment. Am J Respir Crit Care Med 173: 105-111.

3. Matsui K, Tatsuguchi A, Valencia J, Yu Z, Bechtle J, et al. (2000) Extrapulmonary lymphangioleiomyomatosis (LAM): clinicopathologic features in 22 cases. Hum Pathol 31: 12420-1248.

4. Astrinidis A, Khare L, Carsillo T, Smolarek T, Au KS, et al. (2014) Mutationa analysis of the tuberous sclerosis geneTSC2 in patients with pulmonary lymphangioleiomyomatosis. J Med Genet 37: 55-57.

5. Glasgow CG, Taveira-DaSilva A, Pacheco-Rodriguez G, Steagall WK, Tsukada 
Citation: Radzikowska E, Błasińska-Przerwa K, Skrońska P, Wiatr E, Świtaj T, et al. (2016) Lymphangioma in Patients with Pulmonary Lymphangioleiomyomatosis: Results of Sirolimus Treatment. J Cancer Sci Ther 8: 233-239. doi: 10.4172/1948-5956.1000419

$\mathrm{K}$, et al. (2010) Involvement of lymphatics in lymphangioleiomyomatosis. Lymph Res Biol 7: 221-228.

6. Radzikowska E (2015) Lymphangioleiomyomatosis-new treatment perspectives. Lung 193: 467-475.

7. Bissler JJ, Kingswood JC, Radzikowska E, Zonnenberg BA, Frost M, et al. (2013) Everolimus for angiomyolipoma associated with tuberous sclerosis complex or sporadic lymphangioleiomyomatosis (EXIST-2): a multicentre, randomised, double-blind, placebo-controlled trial. Lancet 381: 817- 824.

8. McCormack FX, Inoue Y, Moss J, Singer LG, Strange C, et al. (2011) Efficacy and safety of sirolimus in lymphangioleiomyomatosis. $N$ Eng $J$ Med 364: 1595-1606.

9. Taveira-DaSilva AM, Jones AM, Julien-Williams P, Stylianou M, Moss J (2015) Retrospective review of combined sirolimus and simvastatin therapy in lymphangioleiomyomatosis. Chest 147: 180-187.

10. Yao J, Taveira-DaSilva AM, Jones AM, Julien-Williams $P$, Stylianou M, et al. (2014) Sustained effects of sirolimus on lung function and cystic lung lesions in lymphangioleiomyomatosis. Am J Respir Crit Care Med 190: 1273-1282.

11. Baldi BG, Araujo MS, Freitas CS, Teles GB, Kairalla RA, et al. (2014) Evaluation of the extent of pulmonary cysts and their association with functional variables and serum markers in lymphangioleiomyomatosis (LAM). Lung 192: 967-974.

12. Freitas CSG, Baldi BG, Araújo MS, Heiden GI, Kairalla RA, et al. (2015) Use of sirolimus in the treatment of lymphangioleiomyomatosis: favourable responses in patients with different extrapulmonary manifestations. J Bras Pneumol 41: 275-280.

13. Taveira-DaSilva AM, Hathaway O, Stylianou M, Moss J (2011) Changes in lung function and chylous effusions in patients with lymphangioleiomyomatosis treated with sirolimus. Ann Int Med 154: 797-805.

14. Dickson MA, Schwartz GK, Antonescu CR, Kwiatkowski DJ, Malinowska IA (2013) Extrarenal perivascular epithelioid cell tumours (PEComas) respond to mTOR inhibitors: Clinical and molecular correlations. Int J Cancer 132: 1711-1717.

15. Ellender CM, Williams TJ, Gooi J, Snell GI, Whitford HM (2015) Management of refractory chylothorax in pulmonary lymphangioleiomyomatosis. Respirology Case Reports 3: 72-74.

16. Ando K, Kurihara M, Kataoka H, Ueyama M, Togo S, et al. (2013) The Efficacy and safety of low-dose sirolimus for treatment of lymphangioleiomyomatosis. Respir Investig 51: 175-183.

17. Gibson GJ (1993) Standardized lung function testing. Eur Respir J 16: 1-100.

18. American Thoracic Society (2002) ATS statement: Guidelines for the six-minute walk test. Am J Respir Crit Care Med 166: 111-117.

19. Avila NA, Chen CC, Chu SC, Wu M, Jones EC, et al. (2000) Pulmonary lymphangioleiomyomatosis: correlation of ventilation-perfusion scintigraphy, chest radiography, and CT with pulmonary function tests. Radiology 214: 441-446.

20. Radzikowska E, Jaguś P, Sobiecka M, Chorostowska-Wynimko J, Wiatr E, et al (2015) Correlation of serum vascular endothelial growth factor-D concentration with clinical presentation and course of lymphangioleiomyomatosis. Respir Med 109: 1469-1475.

21. Mohammadieh AM, Bowler SD, Silverstone EJ, Glanville AR, Deborah DH (2013) Everolimus treatment of abdominal lymphangioleiomyoma in five women with sporadic lymphangioleiomyomatosis. Med J Aust 199: s121-s123.

22. Goldberg HJ, Harari S, Cottin V, Rosas IO, Peters E, et al. (2015) Everolimus for the treatment of lymphangioleiomyomatosis: a phase II study. Eur Respir J 46: 783-794.

23. Glasgow CG, Avila NA, Lin JP, Stylianou MP, Moss J (2009) Serum vascula endothelial growth factor-D levels in patients with lymphangioleiomyomatosis reflect lymphatic involvement. Chest 135: 1293-1300.

24. Young LR, Lee HS, Inoune Y, Moss J, Singer LG, et al. (2013) Serum VEGF-D concentration as a biomarker of lymphangioleiomyomatosis severity and treatment response: a prospective analysis of multicenter international lymphangioleiomyomatosis efficacy of sirolimus (MILES) trial. Lancet Respir Med 1: 445-452.

25. Mydlowski T, Radzikowska E, Oniszh K, Sczepulska-Wójcik E, Jagus $P$, et al. (2013) Pneumocystosis in a patient with lymphangioleiomyomatosis. Pneumonol Alerg Pol 81: 61-67. 